\title{
Numerical modelling of tsunami bore impact on low-rise residential buildings using SPH
}

\author{
Gede Pringgana, ${ }^{1, *}$ and $I$ Gede Adi Susila ${ }^{1}$ \\ ${ }^{1}$ Department of Civil Engineering, Universitas Udayana, Denpasar, Indonesia
}

\begin{abstract}
The resilience of buildings subject to tsunami bore impact can be improved by reducing tsunami-induced lateral hydrodynamic pressure by allowing part of the tsunami bore to pass through the buildings via openings and break-away walls. This research investigated the reduction of lateral pressure caused by tsunami bore impact on a low-rise residential building with openings proposed as the prototype of tsunami-resistant house. Numerical method using smoothed particle hydrodynamic (SPH)based software called DualSPHysics was used to create simulation in numerical boundary in the form of a water tank. The tsunami-like bore simulations were generated based on dam-break analogy and were validated against experimental results. Four simulation cases were conducted in this study: Case 1 and Case 2 were dealing with the parameter sensitivity of reservoir height and distance between reservoir and building, while Case 3 and Case 4 were related to the effectiveness of openings and the base elevation of building in reducing wave impact pressures. The numerical modelling results show that the presence of openings and building's base elevation significantly reduced the lateral hydrodynamic pressures on buildings up to $50 \%$ and this could become an effective strategy for improving the resilience of low-rise residential buildings under tsunami bore impact.
\end{abstract}

\section{Introduction}

Reconnaissance missions of the 2004 Indian Ocean Tsunami disaster revealed that the tsunami-induced forces could lead to severe damage or collapse of structures [1]. The severe damages mostly occurred in low-rise residential building structures [2]. Following the 2004 Indian Ocean Tsunami, more attention has been paid to the design of structures against tsunami-induced forces accompanied by the improvement of tsunami early warning systems. The 2004 Indian Ocean tsunami raised public awareness regarding the design guidelines so it can properly account for the tremendous forces and impacts generated by tsunamis.

Recent development in the tsunami-resistant structures design guidelines has heightened the need for accurate prediction of the applied tsunami-induced loading that is profoundly associated with the hydrodynamic forces exerted on structures during a tsunami event. Factors found to be influencing the hydrodynamics forces have been widely explored,

\footnotetext{
*Corresponding author: gedepringgana@unud.ac.id; gdpring@yahoo.com
} 
where [1] stated that there are three fundamental factors for determining the magnitude and application of the hydrodynamic forces: 1) inundation depth, 2) flow velocity, and 3) flow direction. Those factors strongly influenced by the tsunami wave height and wave period, coastal topography and coastal inland roughness.

It is well established from a variety of studies that the hydrodynamic forces play a vital role in the resistance of coastal structures under tsunami loadings. This study, therefore, set out to evaluate the presence of openings on the vertical surfaces and at the bottom part of the building as a simple yet effective strategy for reducing the tsunami hydrodynamics loadings. The methodological approach taken in this study is numerical modeling based on the smoothed particle hydrodynamics ( $\mathrm{SPH}$ ) method to simulate a tsunami-like bores impact on an idealized residential structure. The findings of this study should make an essential contribution to the field of structural and coastal engineering in an attempt to provide the communities the better resilience of residential buildings, especially in lowlying tsunami-prone coastal areas.

\section{Literature review}

\subsection{Tsunami bore}

A tsunami is a long-period wave with the length of wave up to $350 \mathrm{~km}$ which can be triggered by vertical displacement of seabed during earthquakes [3]. The tsunami wave height is moderate in the deep ocean (e.g., 0.5-1 m), but slowly increases as it is approaching the shorelines until it breaks. Broken tsunami waves often inundate the shorelines in the form of a hydraulic bore which is defined as a fast-moving body of water with an onshore mass flux which can be devastating for building structures [4]. The abrupt front of the hydraulic bore has a velocity that its estimation is somewhat difficult to determine because it depends on several factors, including the impoundment depth and the surface frictions. The advancing body of water in the form of the bore that impacting the structure and the resulting bore impact pressures on the structure being located inland, have been explored in several studies [1,3,4]. Experimental modeling of tsunami wave run-up in shallow waters and over a dry bed was conducted by utilizing large wave flumes, showing the similarity of the dam break wave analogy with the tsunami run-up on coastlines $[5,6]$.

\subsection{Numerical simulations of tsunami waves}

One of the main challenges faced by many researchers in the tsunami research area is the expensive cost of experimental testing. Hence, the numerical simulation using computers has increasingly popular since it provides lower cost alternative for research regarding tsunamis. The smoothed particle hydrodynamics (SPH) is a mesh-free method capable of simulating complex free-surface problems such as tsunami waves. As a mesh-free method, the SPH is unrestricted by time-consuming and costly process of generating/ regenerating fine mesh during simulation [5].

Along with rapid growth in the development of hardware technology, there is increasing concern over the hardware acceleration to improve computing performance. In relation to this, an SPH-based software called DualSPHysics has been developed to enable the use of both central processing units (CPUs) and graphics processing units (GPUs) for performing SPH numerical analysis. The performance of SPH modeling can be improved by taking advantage the hardware acceleration given by the utilization of graphics processing units 
(GPUs) that enable the speed up of numerical analysis up to 100 times as compared to that of central processing units (CPUs) time [4].

A considerable amount of literature has been published regarding the efficacy of SPH for simulating tsunami-like waves. A 3-D weakly compressible smoothed particle hydrodynamics (SPH) modeling was conducted by other [7] to simulate the impact of tsunami-like bores on a square cross-section column. The tsunami-like bores were generated using the dam-break analogy following experimental testing performed in a wave flume. The numerical modeling results generally showed good agreement with the experimental data.

\subsection{The effectiveness of openings on tsunami-resistant buildings}

Based on field survey focusing on the 2011 Japan tsunami effects on coastal buildings, it was concluded that the light-frame constructions (e.g., low-rise residential house) could not resist lateral hydrodynamics loading caused by a tsunami with inundation depth of more than few meters or tsunami waves with high flow velocities [5]. To survive from more frequent of such events, it is recommended that the upper-structure of a building should be elevated above the design flood elevation (e.g. the base of 100-year floods or associated tsunamis) by a pile or column foundation [8]. Previous investigations of the presence of openings on building's wall have demonstrated that the openings can reduce the force caused by tsunami wave exerted on the building's wall [9]. Similarly, the breakaway walls located at the lower levels of the building is recommended by [10] to decrease the lateral tsunami forces.

A prototype of the tsunami-resistant house has been developed for post-tsunami reconstruction in Sri Lanka [11]. The 500 square foot house designed with large openings intended to pass through the waves during tsunami events, as can be seen in Fig. 1a. The small-scale model of this tsunami-resistant house, as depicted in Fig. 1b, was experimentally investigated and it was revealed that the openings and also the raised platform were effectively reduced the lateral tsunami loadings [12].

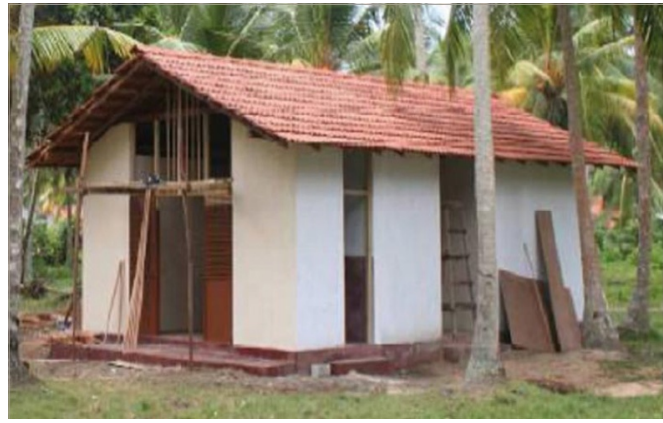

(a)

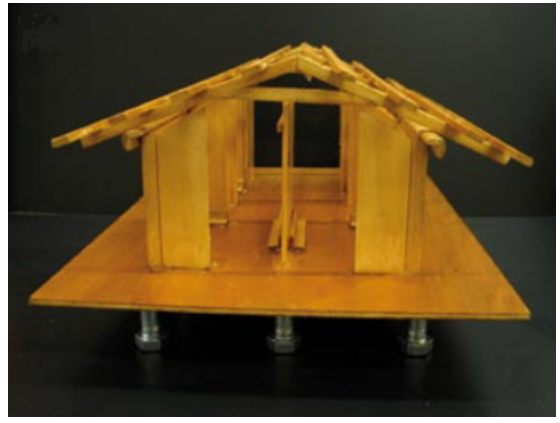

(b)

Fig. 1. The prototype and model of tsunami-resistant house, (a) prototype, (b) experimental smallscale model [12].

\section{Methodology}

\subsection{SPH model validation}

Before conduct the SPH modeling of tsunami-like bore impact on structures, an SPH simulation for validation is performed to ensure the efficacy of the modeling simulations. 
The SPH validation model is performed using an SPH-based software called DualSPHysics v.3. During the validation modeling, the SPH parameters' value is examined so that the modeling results satisfied the results of associated SPH benchmark test case [13].

\subsection{SPH model numerical set up}

Fig. 2 depicts the boundary and numerical set up of SPH model that consists of the water reservoir with length, width and height denoted by $L_{1}, W$, and $H_{w}$, respectively. At the opposite side, a small-scale (1:3) residential house is placed at distance $L_{2}$ from the water reservoir front side. $L_{3}$ denotes the distance from the front face of the idealized building to the rear boundary wall. The probes for measuring water level are positioned at the middle of the boundary, while the pressure probes are mounted at the surface of the house's vertical wall. In this study, the value of $L_{1}, L_{2}$, and $H_{w}$ are varied in association with Case $1 \mathrm{a}, 1 \mathrm{~b}, 1 \mathrm{c}$ and Case 2a, 2b, 2c, as shown in Table 1, to examine their effects in relation to resulting pressures caused by hydraulic bore impacts.

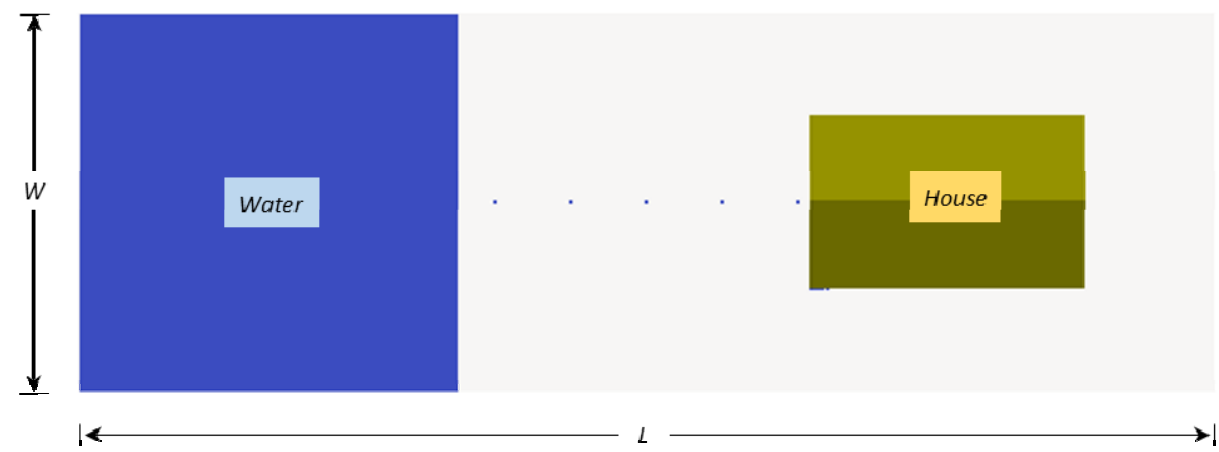

(a) Top view of SPH model

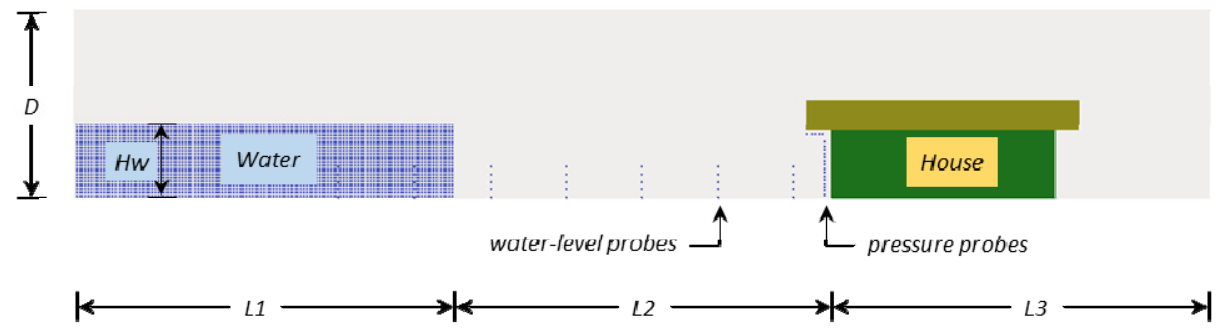

(b) Side view of SPH model

Fig. 2. The numerical set up of SPH model.

The plan of tsunami-resistant house model is illustrated in Fig. 3, where this is a 1/3scale model of the tsunami-resistant house prototype proposed by other [12]. The height of the model's wall and roof are $0.90 \mathrm{~m}$ and $1.33 \mathrm{~m}$, respectively. Fig. 3 shows that the building structure consists of four main cores in the shape of letter-like C and S. The breakaway walls in the plan are marked by lighter lines where they are designed to break and allow part of tsunami waves passing through the buildings during tsunami events. The effectiveness of opening sizes and base elevations observed in this study by placing an idealized structure in orientations vary with the direction of oncoming tsunami bores, as shown in detail by Fig. 4, where they are associated with Case 3a, 3b, 3c and Case 4a, 4b, $4 \mathrm{c}$ in Table 1. 
Table 1. Cases of the SPH simulations

\begin{tabular}{|c|c|c|c|c|c|c|c|}
\hline Case & $\begin{array}{c}\boldsymbol{L}_{\mathbf{2}} \\
(\mathbf{m})\end{array}$ & $\begin{array}{c}\boldsymbol{H}_{\mathbf{w}} \\
(\mathbf{m})\end{array}$ & $\boldsymbol{L}_{\mathbf{2}} / \boldsymbol{H}_{\mathbf{w}}$ & Case & $\begin{array}{c}\text { Opening } \\
\left(\mathbf{m}^{\mathbf{2}}\right)\end{array}$ & $\begin{array}{c}\text { Elevation } \\
(\mathbf{m})\end{array}$ & Impacted area \\
\hline $1 \mathrm{a}$ & 5 & 1 & 5 & $3 \mathrm{a}$ & - & - & Front face \\
\hline $1 \mathrm{~b}$ & 7.5 & 1 & 7.5 & $3 \mathrm{~b}$ & 0.81 & - & Front face \\
\hline $1 \mathrm{c}$ & 10 & 1 & 10 & $3 \mathrm{c}$ & - & 0.167 & Front face \\
\hline 2a & 7.5 & 1 & 7.5 & $4 \mathrm{a}$ & - & - & Side face \\
\hline 2b & 7.5 & 1.5 & 5 & $4 \mathrm{~b}$ & 0.48 & - & Side face \\
\hline 2c & 7.5 & 2 & 3.75 & $4 \mathrm{c}$ & - & 0.167 & Side face \\
\hline
\end{tabular}

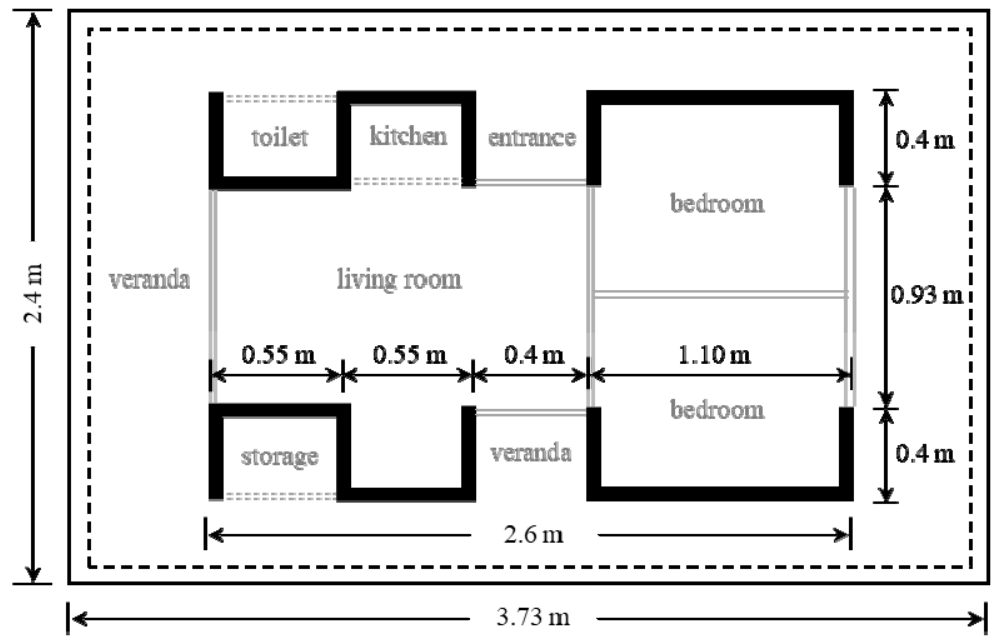

Fig. 3. The plan of tsunami-resistant house model.

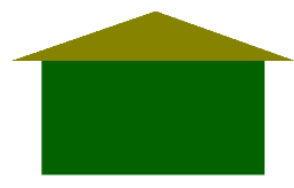

(a)

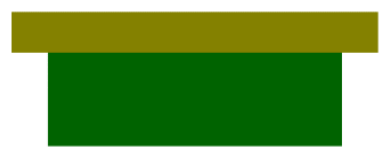

(d)

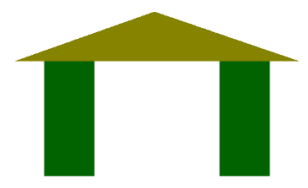

(b)

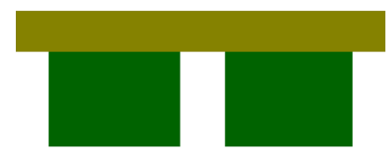

(e)

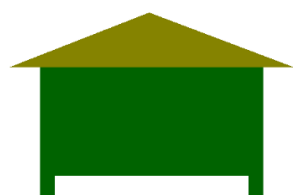

(c)

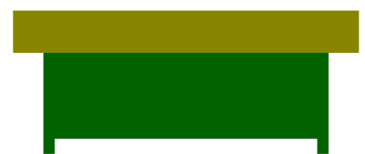

(f)

Fig. 4. The building's impact-target surfaces in SPH simulations, front faces of building models (a, b, c) and side faces of building models (d, e, f), (a) case 3a, (b) case 3b, (c) case 3c, (d) case 4a, (e) case $4 \mathrm{~b}$, (f) case $4 \mathrm{c}$.

Case $3 a, 3 b, 3 c$ compared the pressures exerted on the front faces of buildings, include building without opening on its wall, building with an opening on its wall and building with 
the elevated base, as can be seen in Fig. 4a, 4b, 4c, respectively. Similarly, Cases 4a, 4b, 4c compared the pressures exerted on the side faces of buildings with impacted areas illustrated by Fig. 4d, 4e, 4f. In Table 1, the opening areas of the idealized model are proportional to the opening areas of the prototype and divided by 3 . Similarly, the base elevation of buildings in Case $3 \mathrm{c}$ and Case $4 \mathrm{c}$ is taken $0.5 \mathrm{~m}$ above ground for the prototype and then divided by 3 for the model.

\section{Results and discussions}

The results of SPH modeling for validation satisfied the results of dam break testing used as a benchmark test case [13]. The comparison is made on the water surface elevations and the impact pressures. The details of those comparisons regarding the validation model are not reported in this paper. In the validation model, the diameter of the SPH particle, dp, is taken $1 / 10$ of the smallest length of the building structure. Likewise, the diameter of the SPH particle (dp) used in this study is $0.04 \mathrm{~m}$ where it is also $1 / 10$ of the smallest length of the idealized structure.

The SPH simulations of tsunami-like waves based on the dam break analogy are depicted in Fig. 5 and 6. Fig. 5 shows the initial condition of simulation where the water was at rest. The wave impact on idealized building structure is illustrated in Fig. 6a. Fig. 6b and $6 \mathrm{c}$ show the wave impact on the front and side faces of building and both show the wave flows passing through the buildings, where they are in conjunction with Case $3 \mathrm{~b}$ and $4 \mathrm{~b}$. In Fig. $6 \mathrm{~b}$ and $6 \mathrm{c}$, the roof of buildings are not shown for the clarity of wave flows inside the buildings.

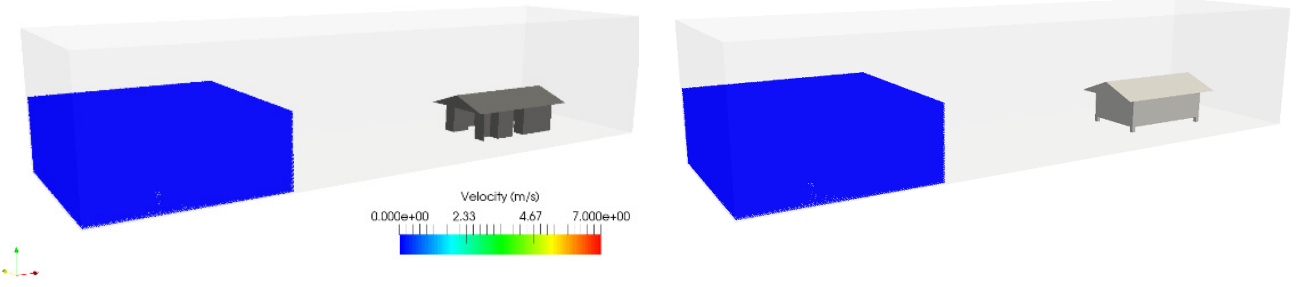

Fig. 5. The initial condition of SPH simulations.

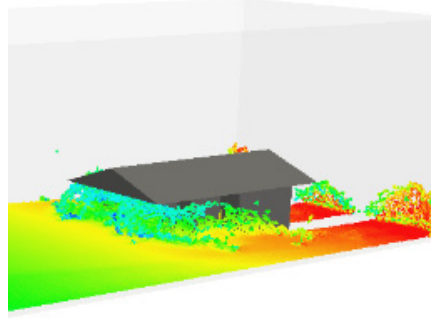

(a)

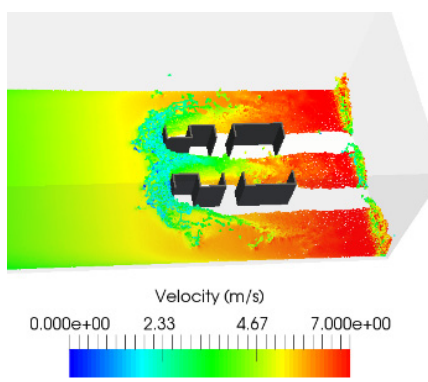

(b)

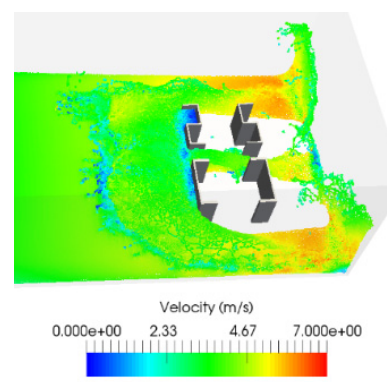

(c)

Fig. 6. Tsunami bore impact on building model.

The pressure of tsunami-like wave impact on building for all cases in this study can be seen in Fig. 7 and Fig. 8. It can be seen from Fig. 7a, especially for Case 1a and 1b, the still water level $\left(H_{w}\right)$ does not affect the maximum pressures significantly, in contrast with the distance between reservoir and structure $\left(L_{2}\right)$ where, for example, the maximum pressure of Case $2 \mathrm{c}$ is more than double the maximum pressure of Case $2 \mathrm{~b}$, as depicted by Fig. $7 \mathrm{~b}$. Thus, to provide optimum impact, the $L_{2}$ value in Case $2 \mathrm{~b}$ was used for following models of 
Case 3 and Case 4. Fig. 8a and Fig. 8b clearly show that the openings and the base elevation of structures effectively reduced the maximum pressure exerted on the surface of structures up to $50 \%$.

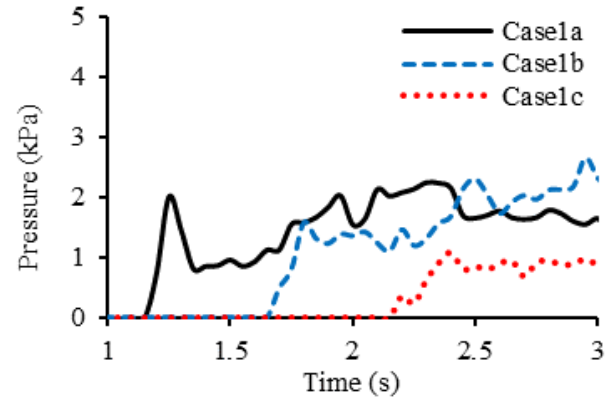

(a)

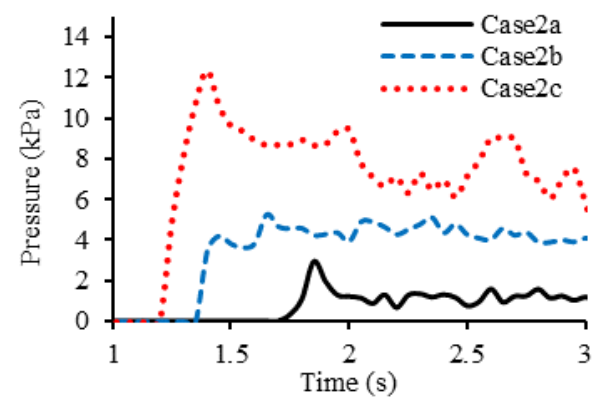

(b)

Fig. 7. SPH impact pressure of Case 1 and Case 2, (a) Pressures based on still water level $\left(H_{\mathrm{w}}\right)$, (b) Pressures based on distance between reservoir and structure $\left(L_{2}\right)$.

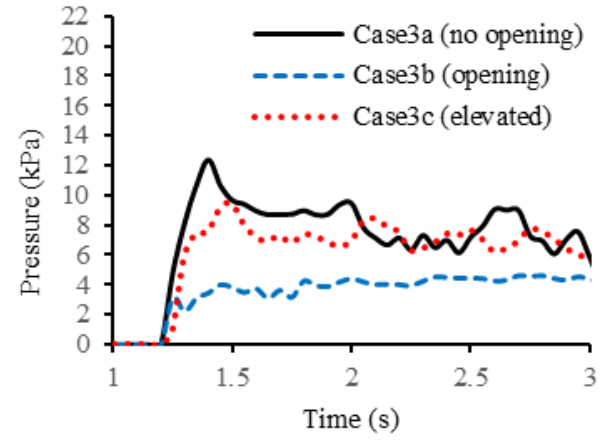

(a)

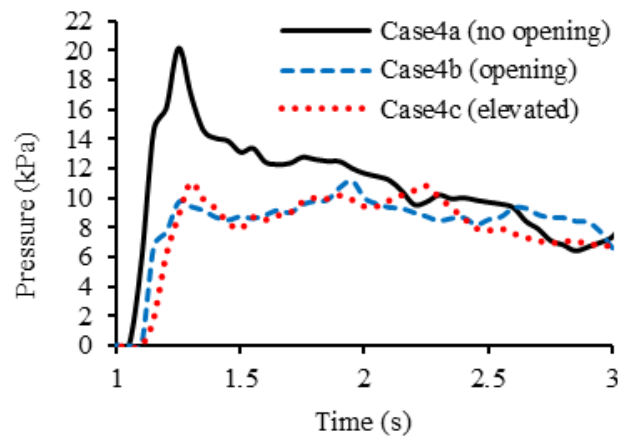

(b)

Fig. 8. SPH impact pressures in relation to Case 3 and Case 4, (a) Pressures on front faces of buildings, (b) Pressures on side faces of buildings.

\section{Conclusions}

From the results of the SPH modeling, some conclusion can be drawn as follows. The height of the water reservoir $\left(H_{w}\right)$ and the distance between water reservoir and structure $\left(L_{2}\right)$ are important modeling parameters that influenced the magnitude of tsunami-like bore impact pressures. The presence of openings on the surface of the tsunami-resistant building and the base elevations of the building significantly reduced the tsunami-like wave impact pressures up to $50 \%$ as shown in Case 4 . The reduction of lateral hydrodynamics pressure on buildings could become an effective solution for improving the resilience of low-rise residential buildings under tsunami bore impact.

The authors acknowledge the contribution of the Faculty of Engineering, Udayana University, to the funding of this research. 


\section{References}

1. I. Nistor, D. Palermo, A. Cornett, T. Al-Faesly, $32^{\text {nd }}$ Internat. Conf. on Coastal Eng. (2010)

2. A. Suppasri, N. Shuto, F. Imamura, S. Koshimura, E. Mas, A.C. Yalciner, Pure and Appl. Geophysics 170, 6 (2012)

3. H. Chanson, S. Aoki, M. Maruyama, Sci. of Tsunami Hazards 20, 5 (2003)

4. G. Pringgana, L.S. Cunningham, B.D. Rogers, Eng. and Comput. Mech. 169, 3 (2016)

5. R. Liu, M.B. Liu, Proc. of World Sci. Singapore (2003)

6. EERI, Special Earthquake Report (2011)

7. P. St-Germain, I. Nistor, R. Townsend, T. Shibayama, Waterway, Port, Coastal, and Ocean Eng. J. 140, 1 (2014)

8. ASCE/SEI 7-16. American Society of Civil Eng. (2017)

9. C. Chinnarasri, N. Thanasisathit, A. Ruangrassamee, S. Weesakul, P. Lukkunaprasit, Maritime Eng. 166 (2013)

10. H. Yeh, I. Robertson, J. Preuss, Washington Div. of Geology and Earth Res. 42 (2005)

11. E. Chen, E. Ho, N. Jallad, R. Lam, J. Lee, Y. Zhou, D.D. Re, L. Berrios, W. Nicolino,

12. C. Ratti, Int. Symp. Disaster Reduction on Coast (2005)

13. N.I. Thusyanthan, S.P.G. Madabhushi, ICE Proc. of Civil Eng. 161, 2 (2008)

14. K.M.T. Kleefsman, G. Fekken, A.E.P. Veldman, B. Iwanowski, B. Buchner, Comput. Phys. J. 206 (2005) 